\title{
Polyester Matrisli Kompozit Özeliklerine Vitrifiye Seramik Sağlık Gereci Atık Miktarının Etkisi
}

\author{
${ }^{* 1,2}$ Gökhan Açıkbaș and ${ }^{2}$ Hasan Göçmez \\ 1. Bilecik Şeyh Edebali Üniversitesi, Meslek Yüksekokulu, Metalurji Programı, 11210, Bilecik, Türkiye \\ 2. Dumlupınar Üniversitesi, Malzeme Bilimi ve Mühendisliği Bölümü, 43266, Kütahya, Türkiye
}

\section{$\ddot{O ̈ z}$}

Seramik sağlık gereçleri alanında Türkiye, Avrupa'da en çok üretim yapan ülke konumundadır. Senelik 320.000 tonluk üretim miktarı, 21,3 milyonluk üretim adediyle ve üretiminin \%60'ını ihraç etmesi nedeniyle ülke ekonomisinde önemli bir konuma sahiptir. Bu nedenle üretim esnasında oluşan atıkların miktarı ve çevreye olan etkisi düşünüldüğünde bu atıkların etkili bir şekilde değerlendirilmesi büyük bir önem arz etmektedir. Üretici firmalar oluşan yaş atığın büyük bir bölümünü değerlendirebilselerde sinterlenmiş ürünün değerlendirilmesinde üretim kısıtlamaları nedeniyle bu mümkün olamamaktadır. Bu durum atıkların farklı alanlarda fayda sağlayacak şekilde değerlendirilmesini zorunlu kılmaktadır. Bu çalışmada seramik sağlık gereçleri alanında üretim yapan bir firmanın atık vitreous china bünyeli sinterlenmiş ürünleri, belirli bir boyut aralığında olacak şekilde ögütülerek polyester matris içerisine farklı oranlarda katılarak kompozit sağlık gereci ürünler (lavabo vb.) elde edilmiştir. Elde edilen kompozit ürünün mekanik ve fiziksel özelliklerine atık sağlık gereci seramik ürün miktarının etkisi tartışılmıştır. Kompozit ürüne, üç nokta eğme, elastik modül, sertlik, \% su emme, \% toplam porozite, bulk yoğunluk, teorik yoğunluk, \% açık porozite testleri yapılmıştır. Elde edilen ürünlerin mikro yapıları, kullanılan tozların tane şekilleri Taramalı Elektron Mikroskobu(SEM)-İkincil Electron(SE) dedektörü kullanılarak analiz edilmiștir. Artan atık seramik miktarı ile kompozit ürünlerde eğme mukavemetinde belirgin bir değișim görülmezken, sertlik ve elastik modul değerleri artmıştır. Artan seramik atık miktarı ile \% su emme değerleri benzer iken $\%$ açık porozite, $\%$ toplam porozite, bulk yoğunluk değerleri artmıştır.

Anahtar Kelime: polyester, kompozit, sağlık gereci, atık

\section{Effect of Vitreous China Sanitaryware Waste Amount on Polyester Matrix Composite Properties}

\author{
${ }^{* 1,2}$ Gökhan Açıkbaş and ${ }^{2}$ Hasan Göçmez \\ 1. Bilecik Şeyh Edebali University, Vocational School, Metallurgy Program, 11210, Bilecik, Turkey \\ 2. Dumlupınar University, Materials Science and Engineering Department, 43266, Kütahya, Turkey
}

\begin{abstract}
The manufacturing of 320000 tons with 21.3 million pieces and exporting $60 \%$ of them make Turkey as leading country at the production of sanitaryware field in the Europa. In the meantime, high amount of sanitaryware production and subsequent effect on the environment requires effective assessment of waste. Although manufacturer effectively utilize wet waste, sintered waste is difficult to regain due to some processing technical hitches. In this respect, the evaluation of waste materials in the various field needs to be investigated. In this study, polyester composite were obtained by adding certain size of vitreous china body waste from company produced sanitaryware products(sink etc.). The mechanical and physical properties of composites were determined in terms of effect of the amount of ceramic waste added into matrix. Elastic module, bending strength, hardness, water absorption, porosity and density were attained. Scanning Electron Microscopy (SEM) determined the grain size and morphology of samples. While the content of ceramic waste addition in the composites increased, bending strength did not change significantly but hardness and elastic modulus improved. Water absorption of composites did not changed whereas open and total porosity and bulk density were increased upon the addition of ceramic waste into polymer matrix.
\end{abstract}

Keywords: polyester, composites, sanitaryware, waste

Sorumlu Yazar: Bilecik Şeyh Edebali Üniversitesi, Meslek Yüksekokulu, Metalurji Programı, 11210, Bilecik, Türkiye, E mail: gokhan.acikbas@bilecik.edu.tr, Tel: 02282141623 


\section{Giriş}

Polimer matrisli kompozitler, günlük yaşantıdan, sanayinin her alanında kullanım imkanı bulan geleceğin malzemeleridir. Seramik sağlık gereçi ürünleri, mutfak, banyo, tuvalet, gibi alanlarda kullanılan, rezervuar, bide, helataşı, pisuar, lavabo, eviye, klozet, duş teknesi vb. Sırlı yada sırsız, beyaz yada renkli ürünlerin genel adıdır [1]. Bu alanda seramiklerin kullanım nedenlerinin başında, yüksek sertlik ve mukavemet özellikleri, yaygın bir şekilde bulunan ekonomik hammadddelerden üretilmesi, polimer matrisli kompozitlerin hafiflik, kolay üretim, yüksek miktarda atık kullanımına imkan tanıması ve elde edilebilir geniş fonksiyonel özellikler vb. sağlaması, metaller ise sahip olduğu yüksek tokluk ve mukavemet değerleri vb. nedenlerle kullanım imkanı bulmaktadır. Ancak soğukluk hissi vermesi(termal iletkenliği yüksek), pahalı olmaları, seramiklere ve polimerlere göre düşük korozyon direnci, estetik açıdan zayıf olmaları, nedeniyle kullanımları kısıtlıdır [2-3]. Kompozit döküm endüstrisi, mühendislik kompozitleri, masif yüzeyler ve mühendislik taşları olmak üzere üretim şekli, polimer/dolgu-takviye oranı ve çeşidi ve dış yüzey jelkot uygulanmasına bağlı olarak üç grupta incelenmektedir. Bu ürünler makine parçalarında kullanımdan banyo ve mutfak gereçlerine kadar çok geniş bir kullanım alanına sahiptir.

Dünya üzerinde bulunan en genel kompozit malzemeler olan ağaç ve kemik doğal kompozit malzemelerdir. Diğer taraftan kompozit malzemeler, havacılık sanayinde, taşımacılıkta, yap1 malzemeleri endüstrisinde, gemi yapımı endüstrisinde, korozyona dayanıklı ekipman yapımında, elektrik ve elektronik sektöründe, çok sayıda spor ekipmanında ve malzemesinde, tarımda, balıkçılıkta ve mekanik üretim sistemleri olmak üzere çok sayıda endüstride sahip olduğu üstün özellikler nedeniyle kullanım alanı bulmaktadir[4-6].

Polimer matrisli kompozit malzemelerde, matris tipi, takviye/dolgu tipi, arayüz etkileşimi üzerine çok sayıda çalışma yer almaktadır. Gürü ve ark.'nın yaptığı çalışmada polyester matrisli kompozit malzeme üretimi gerçekleştirilmiş ve elde edilen malzemelerin mekanik özellikleri incelenmiştir. Mermer/polyester oranları kütlece 3; 3,$5 ; 4 ; 4,5$ ve 5 olarak değiştirilmiştir. Test sonuçları mermer/polyester oranının 4 olduğu durumda malzemenin diğerlerine göre daha yüksek mukavemet ve sertlik değerlerine sahip olduğunu elde etmişlerdir. Optimum oranda elde edilen numunedeki ölçülen sertlik Shore A cinsinden 96, Vickers sertliği $186,3 \mathrm{~kg} / \mathrm{mm} 2$ ve üç noktadan eğmede çekme mukavemeti değeri ise 60,17
N/mm2 olarak bulunmuştur [7]. Sarıbıyık ve ark.'.nın yaptığı çalışmada kuvars takviyeli polimer kompozitlerde kuvarsin yerine $10 \%, 20 \%, 30 \%$, $40 \%$ and $47 \%$ oranlarında atı cam tozu kullanımının basma ve eğme mukavemetine etkisi araştırılmıştır. Atık cam tozu miktarının artışıyla eğme ve basma mukavemeti artmıştır. Reçinenin viskozitesine, partküllerin şekline, boyutuna ve miktarına bağlı olarak kompozitin proses edilebilirliği değişmiştir[8]. Dong ve Davies, fındık kabuğunu dolgu elemanı olarak kullanarak (ağ. $\% 10,20,30$ ve 40) polyester matrisli kompozitlerin eğme dayanımına etkisini araştırmışlardır. Proses kaynaklı gözeneklerin oluşumu ve eğme dayanımına olumsuz etkisi olduğunu belirlemişlerdir. Gözenek içeren numunelerin eğme dayanımları mikro-mekanik modele göre hesaplanmıştır. Deneysel sonuçlar ve teorik hesaplanan eğme dayanımları değerlerinin dolgu elemanı miktarı arttıkça arttığı ve gözenek miktarı arttıkça azaldığ 1 görülmüştür [9].

Doğal yada yapay organik ve inorganik atıkların takviye/dolgu elamanı olarak polimer matrisli kompozit ürünlerin üretimine yönelik çok sayıda çalışma bulunmaktadır. Daha önceki çalışmalarımızda porselen, bor, üreformaldehit, uçucu kül ve mermer tozu atıklarının miktarları ve tane boyut dağılımlarının mekanik ve fiziksel özelliklere etkisi epoksi ve polyester matrislerde kullanımı gerçekleştirilerek araştırılmış, farklı teknikler ile yapı özellik ilişkileri değerlendirilmiştir[10-12]. Diğer çalışmalarımızda ise organik ve inorganik atıkların kompozit yapımında kullanımının etkisi araştırılmış bu bağlamda şerbetçi otu ve mermer tozu ile çam kozalağı ve mermer tozunun polyester matrisde kullanımının kompozitlerin mekanik ve fiziksel özelliklerine etkisi araştırılmış ve farklı teknikler ile yapı özellik ilişkileri incelenmiştir[13,14].

\section{Malzeme ve Metot}

\subsection{Malzemeler}

Polyester malzeme, katalizörleri(hızlandırıcı ve sertleştiricisi) ve kalıp ayırıcısı ile birlikte Poliya, Türkiye firmasından temin edilmiştir. Polyester miktarına bağlı olarak sertleştirici ve hızlandırıcı kompozit karışıma ağ.\%0,1-3 oranında katılmıştır. Polyesterin yoğunluğu $1,076 \mathrm{~g} / \mathrm{cm}^{3}$ 'tür. Dolgu elemanı olarak seramik sağlık gereçleri firmalarına ait vitreous china (VC) pişmiş seramik kırık atığ kullanılmıştır. Seramik kırıkları Fritsch Pulverisette model halkalı öğütücü kullanılarak toz haline getirilmiştir. Öğütülerek hazırlanmış tozlar farklı partikül boyutlarının özelliklere etkisini incelemek için $90 \mu \mathrm{m}, 150 \mu \mathrm{m}$ ve $300 \mu \mathrm{m}$ 'lik eleklerden elenmiştir. Seramik atığının teorik yoğunluğu 
Micromeritics marka Accupyc II 1340 model Hegaz piknometresiyle ölçülerek $2,60 \mathrm{~g} / \mathrm{cm}^{3}$ olarak bulunmuştur. VC seramik atığına ait kimyasal ve mineralojik analizler sırası ile Rigaku marka Primus model XRF (Çizelge 1.) ve Panalytical marka Empyrean model XRD(Şekil-1.) cihazı kullanılarak tespit edilmiştir. VC seramik atığında amorf, kuvars ve mullit fazları tespit edilmiştir. Mullit fazı iğnemsi tane şeklinden dolayı mekanik özeliklere olumlu katısı olan bir fazdır. Şekil 2'de VC seramik atığının SEM-SE görüntüsü verilmiştir. VC seramik atığının düzensiz, keskin köşeli ve kısmen küresel şekilli tanelere sahip olduğu belirlenmiştir. Testlerde kullanilan metal ve polimer kalıplar döküm öncesi kalıp ayırıcı uygulaması yapılarak hazır hale getirilmiştir.

Çizelge 1. VC seramik atığına ait XRF ile yapılmış kimyasal analiz sonucu

\begin{tabular}{|c|c|c|c|c|c|c|c|c|c|c|}
\hline Numune İsmi & $\begin{array}{l}\text { K.K. } \\
\text { Ăg.\% }\end{array}$ & $\begin{array}{l}\mathrm{SiO}_{2} \\
\mathrm{Ağ.} \% \\
\end{array}$ & $\begin{array}{l}\mathrm{Al}_{2} \mathrm{O}_{3} \\
\mathbf{A \breve { g } .} \% \\
\end{array}$ & $\begin{array}{l}\mathrm{TiO}_{2} \\
\text { Ăg.\% }\end{array}$ & $\begin{array}{l}\mathrm{Fe}_{2} \mathrm{O}_{3} \\
\mathrm{Ağ.} \% \\
\end{array}$ & $\begin{array}{l}\mathrm{CaO} \\
\mathrm{Ağ} . \% \\
\end{array}$ & $\begin{array}{l}\text { MgO } \\
\text { Ăg.\% }\end{array}$ & 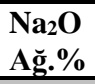 & $\begin{array}{l}\mathrm{K}_{2} \mathrm{O} \\
\text { Ăg.\% } \\
\end{array}$ & $\begin{array}{l}\text { Diğer } \\
\text { Ăg.\% }\end{array}$ \\
\hline VC Bünye & 0,05 & 67,41 & 25,38 & 0,67 & 1,04 & 0,47 & 0,30 & 3,76 & 0,76 & 0,16 \\
\hline
\end{tabular}

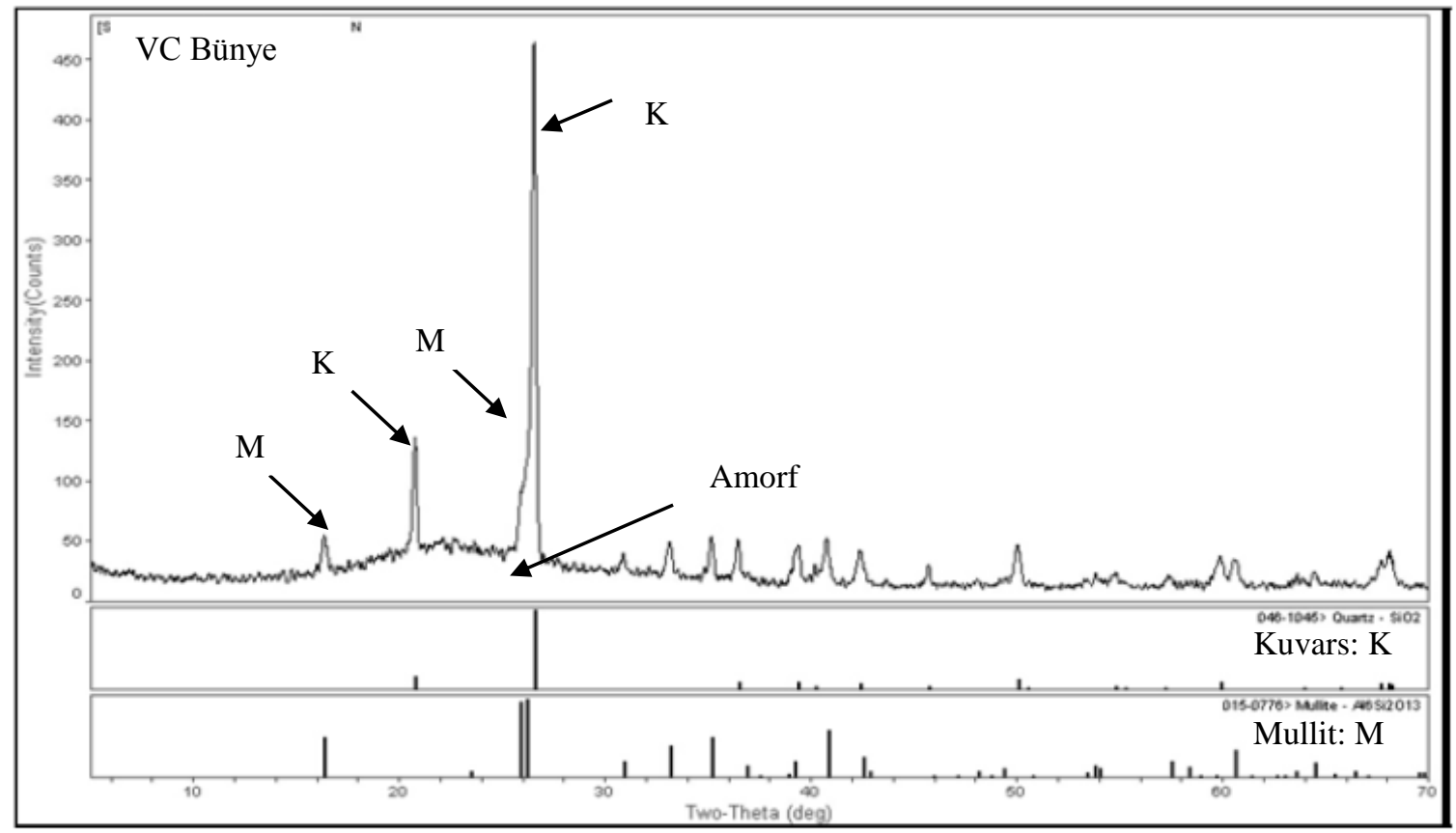

Şekil 1. VC seramik atığına ait mineralojik analiz sonucu

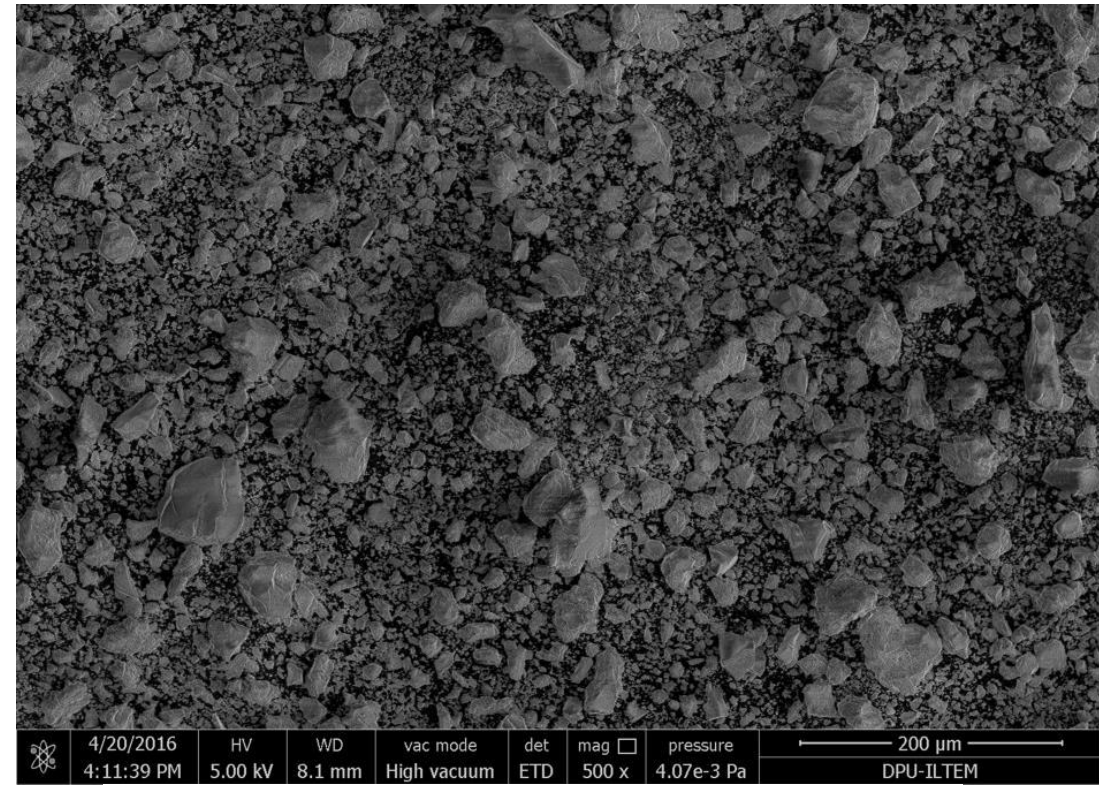

Şekil 2. VC seramik atığına ait SEM-SE görüntüsü, $(<90 \mu \mathrm{m})$ 


\subsection{Kompozit Karışımlarının Hazırlanması}

\subsubsection{Dolgunun Hazırlanması}

Kompozit yapıda kullanılacak, VC seramik kırıkları Fritsch Pulverisette model halkalı ögütücü kullanılarak 1-5 dakika süre ile 1000 rpm'de toz haline getirilmiştir. Ögütülerek hazırlanmış tozlar farklı partikül boyutlarının özelliklere etkisini incelemek için $90 \mu \mathrm{m}, 150 \mu \mathrm{m}$ ve $300 \mu \mathrm{m}$ 'lik eleklerden elenmiştir.

\subsubsection{Kompozit Karışımlarının Hazırlanması ve Döküm}

Çalışmada $90 \mu \mathrm{m}$ altı, $90-150 \mu \mathrm{m}$ arası ve 150 $300 \mu \mathrm{m}$ arası olacak şekilde 3 farklı tane boyutunda, ve $90 \mu \mathrm{m}$ altı toz ile 4 farklı dolgu:reçine oranında karşımlar hazırlanmıştır. Çizelge 2.'de bu karışımlara ait reçete bileşimleri gösterilmiştir. İşlem surasinda belirtilen oranlarda ve tane boyutlarında dolgu malzemesi ve polyester reçine ilk olarak karıştırılmıştır.300-1500 ppm'de hızlarında toplamda 15 dakika, 4 kanatlı karıştırıcı kullanılarak karıştırma işlemi yapılmıştır. Karıştırma işlemi esnasında yapıya hızlandırıcı ilavesi ve vakum işlemi yapılmış olup sertleştirici en son aşamada ilave edilip karışım döküm işlemi için hazır hale getirilmiştir. Bu işlemden sonra karışımlar yapılacak testlere göre hazırlanmış kalıplara dökülmüştür. Şekil 3'de

kompozit üretim ve analiz akış şeması gösterilmiştir.

Çizelge 2. Hazırlanan kompozit karışımlarına ait reçete kodları ve bileşimleri

\begin{tabular}{llllllll}
\hline & \multicolumn{7}{c}{ A ğırlıkça \% } \\
\hline Reçete Kodu & KVC1 & KVC2 & KVC3 & KVC4 & KVC5 & KVC6 & KVC7 \\
Tane Boyut Aralı̆̆ı, $\boldsymbol{\mu m}$ & $<90$ & $<90$ & $<90$ & $<90$ & $<90$ & $90-150$ & $150-300$ \\
Dolgu:Polimer Oranı & 1,50 & 1,22 & 1,00 & 0,67 & 0,43 & 1,22 & 1,22 \\
\hline
\end{tabular}

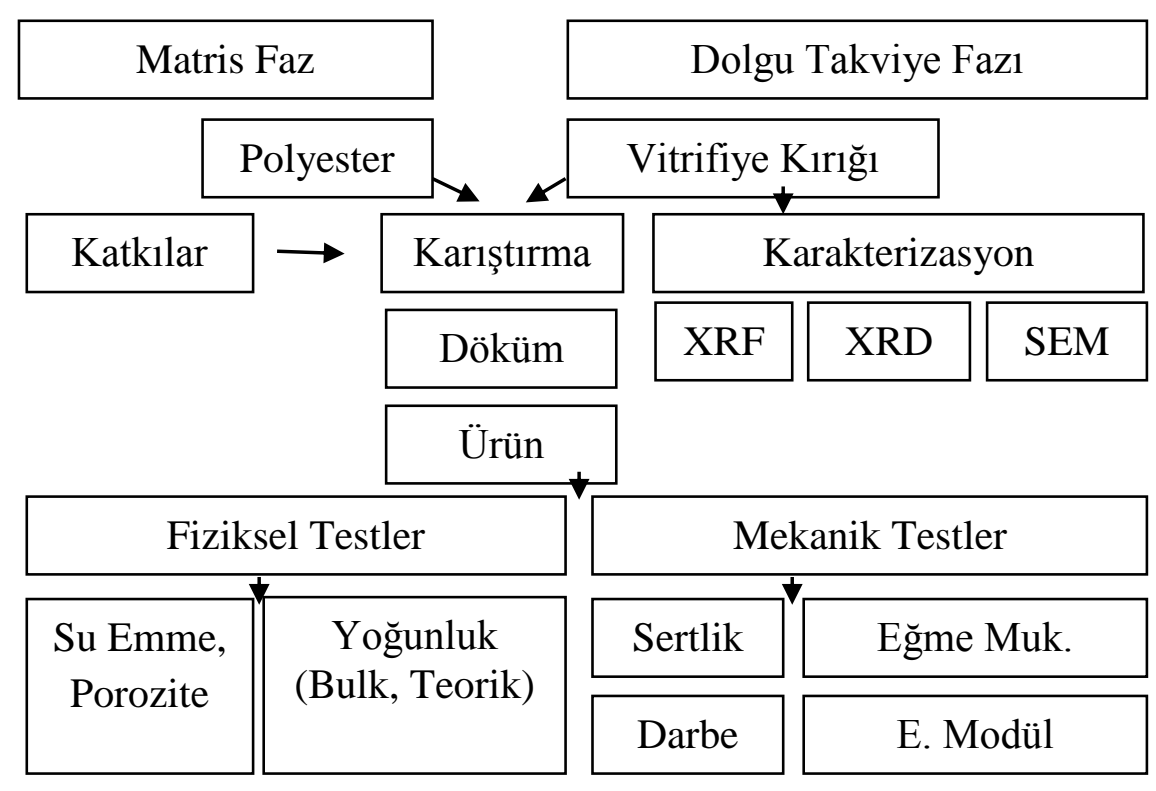

\subsection{Eğme Deneyi}

Üretilen kompozitlerin 3 noktalı eğme dayanımı TS 985 EN ISO 178 standardına göre Shimadzu marka cihazda yapılmıştır. Numuneye üç noktadan uygulanan $2 \mathrm{~mm} / \mathrm{dak}$. hızdaki yük ile eğme mukavemeti, \% uzaması ve belirli alana uygulanan maksimum kuvvet belirlenmiştir. Testler 5 'er adet numuneye uygulanıp ortalama değerler alınmıştır. Eşitlik A.1' göre eğme mukavemeti (MPa)cinsinden hesaplanmıştır. Eşitlik 1' de, $\mathrm{P}=$ Uygulanan yük $(\mathrm{N}), \mathrm{L}=$ Mesnetler arası uzaklık $(\mathrm{mm}), \mathrm{b}=$ Dörtgen kesitli numunenin eni $(\mathrm{mm}), \mathrm{h}=$ Dörtgen kesitli numunenin yüksekliği (mm) dir.

$\sigma_{e \breve{g} m e}=\frac{3 . P . L}{2 . b d^{2}}$

(Eşitlik 1)

\section{4. Ĕ̆mede Elastik Modül}

Kompozitlerin elastik modül değerleri Eşitlik 2 kullanılarak yapılmıştır. Eğme deneyinden elde edilen grafiğgin maksimum kuvvet noktasına kadar olan bölümünden eğim değeri elde edilmiştir. 


$$
E=\frac{L^{3}}{4 W D^{3}} x m
$$

Denklem'de verilen, E-elastik modül, m-eğim, Lmesnetler arası mesafe, W-numunenin genişliği ve D-numunenin kalınlığıdır.

\subsection{Sertlik Testi}

Kare şeklinde $5 * 5 \mathrm{~cm}$ boyutlarında hazırlanmış numunelerin sertlik ölçümleri, $5 \mathrm{~kg}$ sabit yük uygulamalı shore-D sertlik düzeneği ile ölçülmüştür. 5 farklı noktadan ölçülen değerlerin ortalaması alınmıştır.

\subsection{Kompozitlerin Teorik Yoğunluk, Bulk Yoğunluk ve Porozitelerinin Hesaplanması}

Tüm numunelerin yoğunluğu, Arşimet'in su ile yer değiştirme prensibine göre ölçülmüştür. $\mathrm{Bu}$ prensibe göre, bir maddenin sıvı içindeki ağırlığı, o maddenin kuru ağırlığı ile batmaya karşı gösterdiği direnç kuvvetinin farkına eşittir. Eşitlik 3'de yığınsal yoğunluk, Eşitlik 4'de \% Açık Porozite, Eşitlik 5'te \% TY ve Eşitlik 6'da \%TP(toplam porozite) hesaplamaları gösterilmiştir. Kompozit malzemelerin teorik yoğunluğu polyesterin yoğunluğu ve içerdiği dolgu fazın yoğunluğu ve hacim oranına bağlı olarak karışım kuralına göre hesaplanmıştır.

Bulk Yoğunluk $=\frac{W_{1}}{W_{3}-W_{2}} x \rho_{s u}$
$\%$ Açık Porozite $=\frac{W_{3}-W_{1}}{W_{3}-W_{2}} x 100$

(Eşitlik 3)

$\% \mathrm{TY}=\frac{B . Y}{T . Y} x 100$

$\% \mathrm{TP}=100-\% \mathrm{~T} . \mathrm{D}$

(Eşitlik 6)

$W_{l}=$ Kuru a $\breve{g} \iota r l ı k$

$W_{2}=$ Askıda ăglrlık

$W_{3}=S ı v \imath$ sızdırılmış haldeki ă̆ırlıkları

B.Y. = Bulk Yoğunluk

T.Y. $=$ Teorik Yoğunluk

\section{Bulgular}

Azalan dolgu:polyester oranlarında karışımlar hazırlanarak döküm ve son ürün özellikleri tartışılmıştır. Yapılan çalışmada kompozit yapıda polyester maliyeti daha yüksek olduğu için dolgu miktarı döküm özelliklerini ve malzemeden beklenen mekanik ve fiziksel özellikleri karşılayacak şekilde optimum bir değerde elde edilmesi amaçlanmıştır. Yapılan denemelerde dolgu miktarı arttıkça döküm zorlaşırken, dolgu miktarı azaldıkça döküm işlemi kolaylaşmıştır. Döküm işlemi, mekanik ve fiziksel özellikler için ideal karışım oranı 1,22 olarak belirlenmiş bu oranda tane boyutunun özellilere etkiside tartışılmıştır.

\section{Sonuçlar ve Tartışma}

Yüksek dolgu miktarlarında, karışım viskozitesi artarak döküm işlemini zorlaştırmakta ve neticesinde ürünün kalıbı doldurmasını ve homojen yüzey elde edilmesini zorlaştırmaktadır. Uygun olmayan yüzey, mekanik testlerde kompozit üründen beklenen performansın elde edilmesini zorlaştırmaktadır. $\quad \mathrm{Bu}$ nedenle KVC1 numunesinden istenen özellikte test numuneleri bazı testler için elde edilememiştir. Şekil 4.a'ya bakıldığında azalan dolgu miktarı ile eğme mukavemetinde belirgin bir artış görülmemiştir. $\mathrm{Bu}$ durumda test çubuklarının kırık yüzeyleri incelenmiş kırılma noktalarında porlar görülmüştür. Toplam porozite ve açık porozite değerlerinde belirgin bir değişme olmaması ve bu durumun ürünün orta bölgelerinde havanın kürlenme esnasında çıkamayıp birikmesi nedeniyle ürün performasını olumsuz etkilediği düşünülmüştür. İzod darbe dayanımında da(Şekil 4.b), azalan dolgu miktarı ile darbe dayanımının artması eğme mukavemetinde olması beklenen davranış oduğundan ve elde edilen sonuçlar eğme dayanımı ile tam olarak uyuşmadığından bu durum eğme çubuklarında proses kaynaklı olası bir hatayı gösterir niteliktedir. Dolgu fazı artışı ile daha elastik bir yapıya sahip polyester matris daha fazla rijitleşmekte ve daha düşük uzama değerlerinde kırılmaktadır. Bu durum seramik fazın kompozit yap1 içersinde kullanım miktarına bağlı olarak bölgesel gerilim bölgeleri yaratması ve ürünün darbe veya kuvvet uygulanması ile zarar görmesine neden olmaktadır. Elastik modül(Şekil 4.c) ve sertlik değerleri (Şekil 4.d) azalan dolgu fazı miktarı ile azalmıştır. Bu durum rijit ve daha sert olan seramik fazın miktarının azalmasından kaynaklanmaktadır. Azalan dolgu fazı miktarı ile döküm işlemi kolaylaştığı için ürünlerin fiziksel özelliklerinde de iyileşme görülmüş, su emme, açık porozite(Şekil 4.e) değerleri azalmış, \%teorik yoğunluğa ulaşma değeri artarken \% toplam porozite(Şekil 4.f) değerinde azalma görülmüştür. 

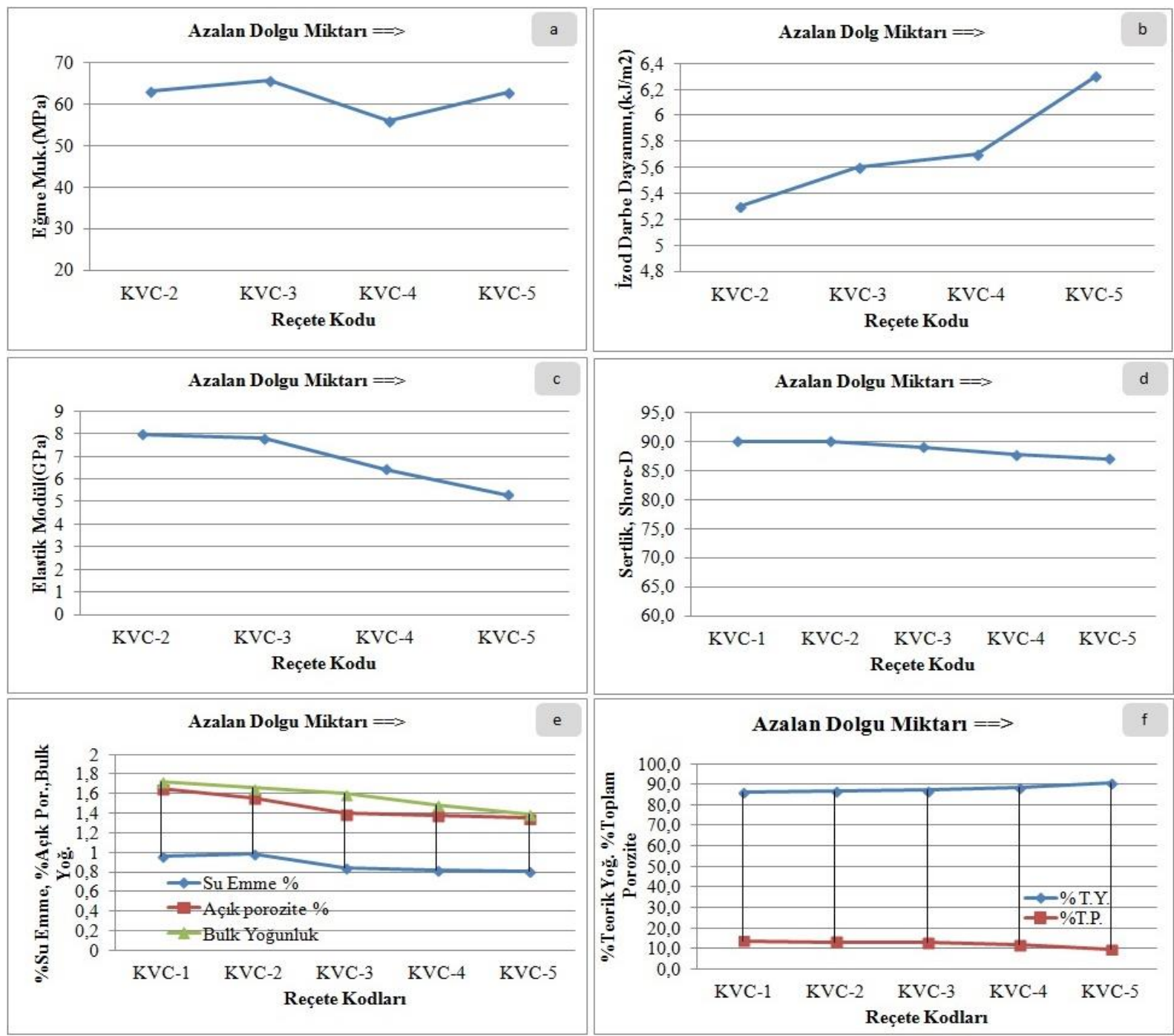

Şekil 4.Farklı dolgu polimer oranlarına ait mekaniksel ve fiziksel analiz sonuçları, a)Eğme Muk., b)Darbe Dayanımı, c) Elastik modül, d) Sertlik, e ve f) Fiziksel özellikler

Optimum dolgu-polimer oranında artan dolgu tane boyutu ile birlikte eğme dayanımında $90 \mu \mathrm{m}$ altı boyuta göre azalma görülmüştür (Şekil 5.a). Bu azalmanın nedeni ince partiküllerde matris-arayüz etkileşiminin kaba partiküllere göre daha iyi olması, kaba partiküllerin kısmende olsa döküm sırasında segrgasyona uğraması nedeniyledir. İzod darbe dayanımı artan dolgu tane boyutu ile artmıştır(Şekil 5.b). Bu durum artan tane boyut ile azalan tane yüzey alanı nedeniyle yap1 daha sünek bir hale büründüğü içindir. Artan dolgu tane boyutu ile elastik modül ve sertlik değerleri azalmıştır(Şekil 5.c,d). Bu durum su emme, açı ve toplam porozite değerleri ile birlikte incelendiğinde, boyut artışıla kompozit yapıda iri tanelerden dolayı segregasyon meydana gelerek mikroyapıda homojeniteyi bozup elastik modülün azalmasını sağlamıştır(Şekil 5.e). Ayrıca artan boyut ile \%toplam porozite değeri (Şekil 5.f) artarak, daha gözenekli bir yapı oluştuğu için elastik modülün azalmasına neden olmuştur. Takviye-matris arayüzey bağlanma derecesi ince partiküllerde daha kuvvetli olduğundan, ince tane boyutunun elastik modül değerine olumlu katkısı olmuştur. Sertlikte artan tane boytuyla azalma görülmüştür. Fakat değişim çok düşük düzeydedir. Düşük tane boyutunda (KVC-2), yüksek tane boyut (KVC-6, KVC-7) değerlerine göre daha düşük toplam porozite değerleri elde edilmiştir. 


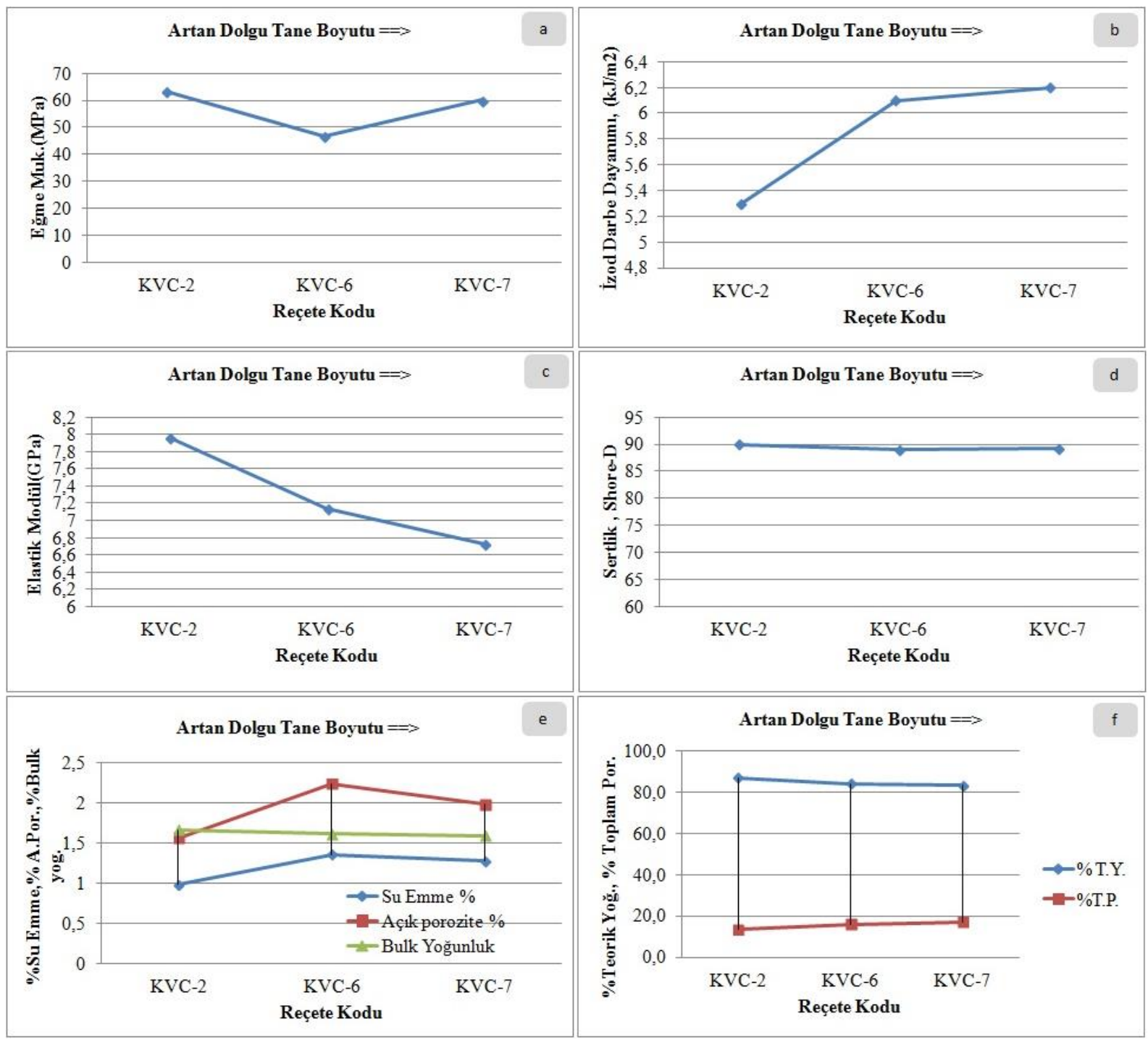

Şekil 5. Farklı dolgu tane boyutlarına ait mekaniksel ve fiziksel analiz sonuçları, a)Eğme Muk., b)Darbe Dayanımı, c) Elastik modül, d) Sertlik, e ve f) Fiziksel özellikler

\section{Genel Sonuçlar}

Kompozit bileşiminde optimum dolgu oranın 1,22 olduğu bu oranın üstündeki değerlerde kompozit dökümünün basınçsız bir şekilde hatasız ve hızlı olarak yapılamıyacağı belirlenmiş olup altındaki değerlerde ise hem üretim hemde mekanik ve teknik özellikler açısından uygun olmayacına karar verilmiş olup 1,22 oranında tane boyutun kompozit özelliklere etki incelenmiş optimum boyut olarak 90 mikron ve altı boyut kullanılmasına karar verilmiştir. Polyester matrise ilave edilen Vitreous China pişmiş seramik atık dolgu miktarının ve tane boyutunun kompozit yapının özellikleri üzerine etkisi belirlenmiş olup bu atıkların kompozit yapımında kullanımının uygun olduğu görülmüştür. Bununla beraber bu dolgu ile farklı özellikler için hibrit kompozit yapılma imkanıda bulunmaktadır. $\mathrm{Bu}$ sayede endüstriyel bir atık, kompozit makine parçasından, endüstriyel kompozit plakakalara, banyo gereçlerine kadar çeşitli ürünlernin üretimi gibi farklı alanlarda katma değer yaratacak bir kullanım alanına sahip olacaktır. VC dolgu içerdiği iğnemsi mullit kristalleri nedeniyle kuvars dolguya alternatif atık bir malzemedir.

\section{Kaynaklar}

[1] D. Fortuna, Ceramic Technology Sanitaryware. SPA: Gruppo editorial efaenza editrice, 2000.

[2] R. Bartusch, "Energy saving potentials in the ceramic industry.", Interceram, vol.53, no 5, pp. 312-317, 2004.

[3] F. Singer, S.S. Singer, Industrial Ceramics. London: Chapman \& Hall, 1963.

[4] B. Harris, Engineering Composite Materials. London: The Institute of Materials, 1999. 
[5] D. Gay, Composite Materials: Design and Applications, Boca Raton: CRC Press-Taylor \&Francis Group, , 2015.

[6] A. B. Strong, Fundamentals of composites manufacturing: materials, methods and applications, Michigan: USA: Society of Manufacturing Engineers, 2008.

[7] M. Gürü, Y. Akyüz, E. Akın, "Mermer Tozu/Polyester Kompozitlerde Dolgu Oranının Mekanik Özelliklere Etkileri”, Politeknik Dergisi, vol. 8, no 3, pp. 271-274, 2005.

[8] M. Sarıbıyı, A. Piskin, A. Sarıbıyı, "The effects of waste glass powder usage on polymer concrete properties", Construction and Building Materials, vol.47. pp.840-44, 2013.

[9] C. Dong, J. I. Davies, "Flexural properties of macadamia nutshell particle reinforced polyester composites", Composites: Part B, vol. 43, pp. 2751-56, 2012.

[10] G. Acikbas, N. C. Acikbas, E. İkizek, M. Özel, A. S. Eker, "Characterization of green epoxy matrix composites filled with ceramic wastes", 2nd International symposium on innovative technologies in engineering and science ISITES2014, Karabük Ünivrsitesi, Karabük, 597606, (2014).
[11] G. Acikbas, N. C. Acikbas, "Epoxy Matrix Composites Containing Urea Formaldehyde Waste Particulate Filler", Waste and Biomass Valorization, DOI: 10.1007/s12649-016-9651-9, pp.1-10, 2016.

[12] T. Pehlivan, A. Akbulut, Ç. Furat, G. Açıkbaş, Ç. Açıkgöz, "Mermer atiklari ve çinko oksit/ külçe pirinç üretim tesisi cürufunun polyester matriksli kompozit malzemelerin özelliklerine etkisi”, 2. Ulusal Kimya Mühendisliği Öğrenci Kongresi 2.UKMÖK, Ankara Üniversitesi, Ankara, (2013).

[13] E. M. Andoglu, A. A. Borazan, G. Acikbas, "Investigation of mechanical properties of polyester/marble dust and hop wastes reinforced composite material", in Proceedings of 14th International conference on environmental science and technology Cest2015, (Sep. 3-5 2015, Rhodes, Greece 2015).

[14] Gokdai D, Akpinar Borazan A, Acikbas G. Effect of marble: pine cone waste ratios on mechanical properties of polyester matrix composites. in Proceedings of 14th International conference on environmental science and technology Cest2015, (Sep. 3-5 2015, Rhodes, Greece 2015). 